\title{
A study of the obstetric and perinatal outcomes of eclampsia and the use of levetiracetam in its management
}

\author{
Meena N. Satia, Manali P. Shilotri* \\ Department of Obstetrics and Gynecology, Seth Gordhandas Sunderdas Medical College and King Edward VII \\ Memorial Hospital, Mumbai, Maharashtra, India \\ Received: 17 September 2016 \\ Accepted: 15 October 2016

\section{*Correspondence:} \\ Dr. Manali P. Shilotri, \\ E-mail: manali.shilotri@gmail.com \\ Copyright: () the author(s), publisher and licensee Medip Academy. This is an open-access article distributed under \\ the terms of the Creative Commons Attribution Non-Commercial License, which permits unrestricted non-commercial \\ use, distribution, and reproduction in any medium, provided the original work is properly cited.
}

\begin{abstract}
Background: Hypertensive disorders are a common cause of maternal morbidity and mortality complicating 3 to $10 \%$ of pregnancies. Eclampsia is a major complication of hypertensive disorders of pregnancy, particularly in developing countries, resulting in poor foeto-maternal outcomes. In some cases of eclampsia use of the gold standard i.e. magnesium sulphate, is restricted and is sometimes ineffective when used as monotherapy. Levetiracetam is an anti-epileptic drug that is relatively safe in pregnancy, does not require intensive monitoring and has potential use in eclampsia. The primary aim of this study was to establish the incidence of eclampsia and its maternal and perinatal outcomes. It also aimed at studying the utility of levetiracetam in the treatment of eclampsia.

Methods: It is a retrospective, observational study conducted at Seth G. S. Medical College and K.E.M Hospital, Mumbai (a tertiary care centre). Data of a period of one year was collected from hospital records. The eclamptic patients' demographic profile, maternal and perinatal outcomes and the use of levetiracetam were noted.

Results: The incidence of hypertensive disorders of pregnancy was $7.53 \%$ while that of eclampsia was $0.737 \%$. The maternal and perinatal case fatality rates were $18 \%$ and $26 \%$ respectively. $50 \%$ of the cases had other concurrent maternal complications. $44.11 \%$ of the live births required neonatal intensive care unit admission. $55 \%$ of the cases who were treated with levetiracetam, either as monotherapy or in combination with magnesium sulphate, made a complete recovery.

Conclusions: The significant number of hypertensive disorders of pregnancy complicated by eclampsia and its associated co-morbidities indicate the need for early detection of hypertension in pregnancy and timely intervention.
\end{abstract}

Keywords: Eclampsia, Hypertension, Maternal mortality, Levetiracetam

\section{INTRODUCTION}

Hypertension in pregnancy is described as systolic blood pressure $140 \mathrm{mmHg}$ or more and/or diastolic blood pressure $90 \mathrm{mmHg}$ or more, recorded on two occasions at least 6 hours apart and within 7 days. The spectrum of hypertensive disorders in pregnancy includes gestational hypertension, pre-eclampsia and eclampsia syndrome, chronic hypertension and pre-eclampsia superimposed on chronic hypertension. These disorders are a common cause of maternal morbidity and mortality, complicating 3 to $10 \%$ of all pregnancies.
Eclampsia is a syndrome complex peculiar to a pregnant, parturient or a puerperal woman and is characterized by tonic-clonic convulsions and/or, occurring after 20 weeks of gestation in a patient with hypertension. It is an obstetric emergency requiring prompt management at a tertiary care institution. Eclampsia is an important direct obstetric cause of maternal mortality with death occurring in 4.9 to $7.8 \%$ of cases. ${ }^{2,3}$ In developed countries incidence of eclampsia is 1 in 1808 while in developing countries it may be as high as 1 in 115 deliveries. ${ }^{3}$ Perinatal morbidity and mortality is high in cases of eclampsia with occurrence of complications like 
stillbirths, preterm birth and small for gestational age. Early detection and effective management of hypertensive disorders in pregnancy can reduce the incidence of eclampsia. The World Health Organization (WHO) also promotes the best possible clinical practices for the management of hypertensive disorders in pregnancy and has laid down guidelines based on evidence-informed recommendations. Our study will help in determining the burden of the disease at a tertiary care centre in a developing country like India and measures that can be taken to reduce the incidence of eclampsia.

\section{METHODS}

It is a retrospective, observational study conducted at Seth G. S. Medical College and K.E.M Hospital, Mumbai (a tertiary care centre). Data of a period of one year was collected from hospital records of 1st January, 2015 to 31st December, 2015. The eclamptic patients' demographic profile, maternal and perinatal outcomes and the use of levetiracetam were noted.

\section{RESULTS}

\section{Incidence}

At our hospital, over a period of one year, there were a total of 6780 deliveries of which $511(7.53 \%)$ women had hypertension in pregnancy. 50 of those women had eclampsia resulting in an incidence of $0.737 \%$ (Table 1 ).

Table 1: Incidence of hypertensive disorders in pregnancy.

\begin{tabular}{|ll|}
\hline $\begin{array}{l}\text { Incidence of hypertensive disorders } \\
\text { Number of deliveries in the study } \\
\text { period }\end{array}$ & 6780 \\
\hline $\begin{array}{l}\text { Number of cases of hypertensive } \\
\text { disorders in pregnancy }\end{array}$ & 511 \\
\hline $\begin{array}{l}\text { Incidence of hypertensive disorders in } \\
\text { pregnancy }\end{array}$ & $7.53 \%$ \\
\hline Number of cases of eclampsia & 50 \\
\hline Incidence of eclampsia & $0.737 \%$ \\
\hline $\begin{array}{l}\text { Percentage of hypertensive disorders in } \\
\text { pregnancy with eclampsia }\end{array}$ & $9.78 \%$ \\
\hline
\end{tabular}

\section{Demographic and clinical profile}

$92 \%$ of the patients were transferred to our centre from peripheral hospitals in view of hypertension in pregnancy while only $8 \%$ of the eclamptic patients were antenatally registered at our hospital.

The mean maternal age at the time of presentation was 25 years.

Eclampsia was more commonly seen in primiparous women $(66 \%)$ as compared to multiparous women $(34 \%)$.
Eclampsia presented most often in the antepartum period, followed by intrapartum and the postpartum period respectively.

The mean gestational age of antepartum eclampsia at the time of presentation was 35 to 36 weeks. The distribution of antepartum eclampsia cases as per gestational age at the time of presentation is given in Table 2 .

Table 2: Distribution of antepartum eclampsia as per gestational age.

\begin{tabular}{|lll|}
\hline $\begin{array}{l}\text { Gestational age } \\
\text { (in weeks) }\end{array}$ & $\begin{array}{l}\text { Number of } \\
\text { cases }\end{array}$ & $\begin{array}{l}\text { Percentage of } \\
\text { cases }\end{array}$ \\
\hline $25-30$ & 5 & 10 \\
\hline $30-34$ & 9 & 18 \\
\hline $34-37$ & 19 & 38 \\
\hline$\geq 37$ & 17 & 34 \\
\hline
\end{tabular}

\section{Obstetric outcome}

As the definitive treatment for eclampsia is termination of pregnancy, all patients of antepartum eclampsia were delivered by vaginal delivery, assisted vaginal delivery (forceps or vacuum application) or lower segment caesarean section. The distribution of patients as per mode of delivery is given in.

The most common indication for caesarean section was foetal distress $(41 \%)$. The other indications were meconium stained amniotic fluid, abruption, nonprogress of labour, failure of induction and previous lower segment caesarean section not willing for vaginal birth after caesarean section (Table 3).

Table 3: Indications for caesarean section.

\begin{tabular}{|ll|}
\hline Indication of caesarean section & $\begin{array}{l}\text { Percentage of } \\
\text { cases }\end{array}$ \\
\hline Foetal distress & 41.17 \\
\hline Meconium stained amniotic fluid & 23.52 \\
\hline Abruption & 11.76 \\
\hline Non-progress of labour & 11.76 \\
\hline Failure of induction & 5.88 \\
\hline $\begin{array}{l}\text { Previous LSCS not willing for } \\
\text { vaginal birth after caesarean section }\end{array}$ & 5.88 \\
\hline
\end{tabular}

$50 \%$ of all eclampsia cases had one or more additional complications such as HELLP syndrome, posterior reversible encephalopathy syndrome (PRES), acute kidney injury (AKI), disseminated intravascular coagulation (DIC), abruption, intracranial bleed and aspiration pneumonia. $12 \%$ of the patients had other miscellaneous complications such as acute respiratory distress syndrome, postpartum haemorrhage, pituitary infarct, proliferative retinopathy, retinal haemorrhage and status eclampticus. 
$28 \%$ of the patients required intensive care unit admission and $22 \%$ required mechanical ventilation. $34 \%$ of the patients required blood and/or blood products transfusion for correction of anaemia or DIC.

\section{Maternal mortality}

In our study there were 9 maternal deaths out of 50 eclampsia cases (case fatality rate 18\%). The leading cause of death was DIC (44\%), other causes being acute kidney injury, intracranial bleed and hepatic failure. The maternal mortality ratio for eclampsia in our study was 137.25 per lakh live births. The percentage of mortality due to eclampsia amongst all maternal deaths was $11.53 \%$. The percentage of mortality due to eclampsia amongst direct obstetric deaths was $40.90 \%$. Thus eclampsia was a major cause of direct obstetric deaths.

\section{Perinatal morbidity and mortality}

Most of the babies born to women with eclampsia in our study had a birth weight of 2 to $2.5 \mathrm{~kg}$. $83.33 \%$ of the babies were low birth weight i.e. $<2.5 \mathrm{~kg}$. $31.25 \%$ of the babies required neonatal intensive care unit admission either due to low birth weight as a result of prematurity or intrauterine growth restriction or birth asphyxia. $28 \%$ of the cases had stillbirths, the leading cause being prematurity. There were no early neonatal deaths. The perinatal mortality rate in cases of eclampsia observed in our study was $26 \%$.

\section{Experience with levetiracetam}

Magnesium sulphate therapy either by Pritchard's regimen or Zuspan regimen was started as primary anticonvulsant therapy in 47 out of the 50 cases. Levetiracetam was administered in the remaining 3 cases instead of magnesium sulphate in view of raised creatinine. Magnesium sulphate had to be discontinued in 9 cases due to rising creatinine with oliguria (7 cases) and suspected magnesium toxicity (2 cases), as repeated monitoring of serum magnesium levels was not possible due to financial constraints. 5 out of these cases were started on levetiracetam.

2 out of the remaining 38 cases developed convulsions despite magnesium sulphate therapy. These patients were given levetiracetam in addition to the standard magnesium sulphate therapy.

Levetiracetam was administered as 1 gram loading dose followed by $500 \mathrm{mg}$ bd intravenously, in all cases. A total of 10 cases were treated with levetiracetam; 3 as primary therapy, 5 as alternative therapy after discontinuing magnesium sulphate and 2 as additional therapy with magnesium sulphate. The obstetric and perinatal outcome of these 10 cases is given in Table 4 . No other side effects of the drug were noted. 1 out of the 10 patients, who was given levetiracetam as additional therapy, continued to have convulsions despite initiating additional therapy and the patient had 'status eclampticus'. She succumbed to her illness soon after. However, the remaining 9 of the 10 patients who were given levetiracetam did not develop any convulsions after initiation of therapy.

Table 4: Obstetric and perinatal outcomes of patients given levetiracetam.

\begin{tabular}{|llllllll|}
\hline & \multicolumn{2}{l}{ Obstetric outcome } & & Perinatal & Tutcome \\
\hline & ICU & Mortality & $\begin{array}{l}\text { Complete } \\
\text { recovery }\end{array}$ & ICU stay & Mortality & $\begin{array}{l}\text { Good } \\
\text { APGAR }\end{array}$ \\
\hline Primary therapy & 2 & 1 & 2 & 1 & $\begin{array}{l}2 \\
(1 \text { undelivered) }\end{array}$ & - & 3 \\
\hline $\begin{array}{l}\text { Alternative } \\
\text { therapy }\end{array}$ & 3 & 2 & 3 & 1 & 3 & 1 & 5 \\
\hline $\begin{array}{l}\text { Additional } \\
\text { therapy }\end{array}$ & 2 & 1 & 1 & 1 & 1 (undelivered) & - & 2 \\
\hline
\end{tabular}

Table 5: Comparative study of incidence, demographic and clinical profile of eclampsia.

\begin{tabular}{|c|c|c|c|c|c|}
\hline Parameter & Our study & Sajith $\mathbf{M}$ et $\mathbf{a l}^{5}$ & Sunita TH et al $^{6}$ & Singh S et al $^{7}$ & Arora $\mathbf{R}$ et $\mathbf{a l}^{3}$ \\
\hline Incidence & $0.737 \%$ & $0.6 \%$ & $1 \%$ & $3.2 \%$ & $0.87 \%$ \\
\hline Parity & $\begin{array}{l}\text { Primiparous } \\
(66 \%)\end{array}$ & & $\begin{array}{l}\text { Primiparous } \\
(79 \%)\end{array}$ & $\begin{array}{l}\text { Primiparous } \\
(82 \%)\end{array}$ & \\
\hline Peak Maternal age & $25-30$ years & $18-22$ years & 21-25 years & & \\
\hline $\begin{array}{l}\text { Time of } \\
\text { presentation }\end{array}$ & $\begin{array}{l}\text { Antepartum } \\
(54 \%)\end{array}$ & & $\begin{array}{l}\text { Antepartum } \\
(56 \%)\end{array}$ & $\begin{array}{l}\text { Antepartum- } \\
\text { intrapartum } \\
(68.3 \%)\end{array}$ & $\begin{array}{l}\text { Antepartum } \\
(47 \%)\end{array}$ \\
\hline $\begin{array}{l}\text { Peak gestational } \\
\text { age at presentation }\end{array}$ & 34-37 weeks & & $>37$ weeks & $>37$ weeks & \\
\hline
\end{tabular}




\section{DISCUSSION}

Pre-eclampsia is a condition involving multiple organ systems and is peculiar to pregnancy as the pathophysiology stems from the changes occurring during pregnancy. It most commonly manifests as hypertension and proteinuria, with or without signs of involvement of other organ systems such as raised hepatic enzymes, thrombocytopenia, pulmonary oedema, cardiac failure, intrauterine growth restriction etc. Patients may lack any one of these signs and symptoms and still have pre-eclampsia. One of the dreaded complications of pre-eclampsia is its evolution to eclampsia. Eclampsia is defined as the development of seizures and/or coma, not attributable to any other cause, during pregnancy or puerperium in a woman with preeclampsia. They are thought to occur due to increased release of excitatory neurotransmitters like glutamate, large scale depolarization of neurons and bursts of action potential. ${ }^{4}$ Most convulsions last for a minute or less before stopping spontaneously. If they are continuous, without a break, the woman is said to be in 'status eclampticus', which is extremely dangerous. Often there are one or more premonitory symptoms preceding the convulsions such as intense headache, blurring of vision, restlessness, and epigastric or right upper quadrant abdominal pain.

Eclampsia most commonly affects young, primiparous women in the antepartum period, as was seen in our and other similar studies. A comparative study of the incidence, demographic and clinical profile of patients with eclampsia is given in Table 5 .

Eclampsia can further be complicated, as seen in our study in 50\% of the patients, by acute renal failure, HELLP syndrome, posterior reversible encephalopathy syndrome (PRES), acute kidney injury (AKI), disseminated intravascular coagulation (DIC), abruption, intracranial bleed and aspiration pneumonia, acute respiratory distress syndrome, pulmonary oedema, cardiac failure, postpartum haemorrhage, retinal haemorrhage and status eclampticus, requiring constant monitoring and services of intensive care units. These patients have a high mortality rate, as seen in our study. The case fatality rate was $18 \%$ and $40 \%$ of the direct obstetric deaths were caused by eclampsia. Thus, effective management of eclampsia will lead to a significant reduction in maternal mortality caused by direct obstetric causes.

Eclampsia is also associated with a poor perinatal outcome. It results in stillbirths, preterm birth and birth asphyxia. In our study, almost a third of the neonates required admission in the intensive care unit either due to low birth weight (caused by prematurity and/or intrauterine growth restriction) or birth asphyxia; however there were no early neonatal deaths. The stillbirth rate amongst cases of eclampsia was $28 \%$. Thus, a good neonatal intensive care unit is required for a better perinatal outcome. A comparative study of the obstetric and perinatal outcomes is given in Table 6 .

Table 6: Comparative study of obstetric and perinatal outcomes of eclampsia.

\begin{tabular}{|lllll|}
\hline & $\begin{array}{l}\text { Our } \\
\text { study }\end{array}$ & $\begin{array}{l}\text { Sunita } \\
\text { TH et al }\end{array}$ & $\begin{array}{l}\text { Singh } \\
\text { S et al }\end{array}$ & $\begin{array}{l}\text { Arora } \\
\text { R et al }\end{array}$ \\
\hline $\begin{array}{l}\text { Case fatality } \\
\text { rate }\end{array}$ & $18 \%$ & $4 \%$ & $4.4 \%$ & $7.8 \%$ \\
\hline $\begin{array}{l}\text { Perinatal } \\
\text { mortality rate }\end{array}$ & $26 \%$ & $19 \%$ & $32.93 \%$ & \\
\hline
\end{tabular}

The management of eclampsia involves initiation of supportive treatment, control of hypertension to prevent further complications and prevention of further convulsions while planning for termination of pregnancy. Magnesium sulphate is the gold standard for prevention and treatment of convulsions in eclampsia. Its use in severe pre-eclampsia for prevention of eclampsia has shown a reduction in the incidence of eclampsia by $58 \%$ and a significant decrease in the maternal mortality. ${ }^{8}$ Magnesium toxicity in the form of respiratory depression and arrest, although rare, can occur especially in cases of impaired renal clearance and acute kidney injury which is seen in up to $14 \%$ of patients in our case study. Use of maintenance doses of magnesium sulphate in such cases requires strict serum magnesium levels monitoring. This continuous monitoring of serum magnesium levels may not be possible in resource-restricted set ups like in developing countries. Thus there is a need for the study of alternative anti-epileptic drugs that are relatively safer in such conditions, effective and do not require drug level monitoring for the management of eclampsia. In our institution, levetiracetam has been used by physicians and obstetricians for the management of certain cases of eclampsia where use of magnesium sulphate was restricted.

Levetiracetam is an anti-epileptic drug that works through various mechanisms such as inhibition of voltage-dependent $\mathrm{N}$-type calcium channels, binding to synaptic proteins that modulate neurotransmitter release and facilitation of GABA-ergic inhibition. It is a category $\mathrm{C}$ drug, i.e. it can be used in pregnancy with caution if benefits outweigh risks. Although the number of cases in our study is small, in view of the lack of any obvious side effects and favourable outcome seen in the cases given levetiracetam, further evaluation of this anti-epileptic drug and its potential use in eclampsia could be undertaken.

\section{CONCLUSION}

Eclampsia is a significant cause of poor maternal and perinatal outcome. Management of eclampsia requires a multidisciplinary approach with co-ordination between the obstetrician, physician, intensive care specialist, anaesthetist and neonatologist. Availability of intensive care for the mother and neonate is a pre-requisite. Patient 
education regarding need for regular antenatal visits is needed for early diagnosis and management of hypertensive disorders in pregnancy thus reducing the incidence of eclampsia. Levetiracetam may be further evaluated for use in cases where magnesium sulphate therapy cannot be administered for any reason.

\section{ACKNOWLEDGEMENTS}

The authors would like to thanks all my colleagues at the Department of Obstetrics and Gynaecology, Seth G.S.M.C and K.E.M. Hospital, Mumbai.

Funding: No funding sources Conflict of interest: None declared

Ethical approval: The study was approved by the Institutional Ethics Committee

\section{REFERENCES}

1. Lo JO, Mission JF, Caughey AB. Hypertensive disease of pregnancy and maternal mortality. Curr Opin Obstet Gynecol. 2013;25(2):124-32.

2. Sarkar M, Basak S, Mondal S, Das S, Roy D, Mandal J, et al. Maternal mortality associated with eclampsia in an Indian medical college: a four year retrospective study. Int Res J Med Sci. 2013;4(10):394-8.

3. Arora R, Ganguli RP, Swain S, Oumachigui A, Rajaram P. Determinants of Maternal Mortality in
Eclampsia in India. Australian and New Zealand Journal of Obstetrics and Gynaecology, 1994:34:537-9.

4. Meldrum BS. Implications for neuroprotective treatments. Prog Brain Res. 2002;135:487-95.

5. Sajith M, Nimbargi V, Modi A, Sumariya R, Pawar A. Incidence of pregnancy induced hypertension and prescription pattern of antihypertensive drugs in pregnancy. International Journal of Pharma Sciences and Research. 2014:5(4):163-70.

6. Sunita TH, Desai RM. Eclampsia in a Teaching Hospital: Incidence, clinical profile and response to Magnesium Sulphate by Zuspan's regimen. 2013:4(2):1-5.

7. Singh S, Behera A. Eclampsia In Eastern India: Incidence, Demographic Profile And Response To Three Different Anticonvulsant Regimes Of Magnesium Sulphate. The Internet Journal of Gynecology and Obstetrics. 2010;15(2).

8. Magpie Trial Follow-Up Study Collaborative Group. The Magpie Trial: A randomised trial comparing magnesium sulphate with placebo for pre-eclampsia. Outcome for women at 2 years. BJOG. 2007;114(3):300-9.

Cite this article as: Satia MN, Shilotri MP. A study of the obstetric and perinatal outcomes of eclampsia and the use of levetiracetam in its management. Int $\mathbf{J}$ Reprod Contracept Obstet Gynecol 2016;5:4266-70. 